\title{
Kant: Leibniz E A Anfibolia dos Conceitos de Reflexão
}

\author{
[KANT: LEIBNIZ AND THE AMPHIBOLIA OF REFLECTION CONCEPTS]
}

\author{
Maria Clara Cescato * \\ Universidade Federal da Paraíba, Brasil
}

\begin{abstract}
Resumo: Na seção sobre a Anfibolia dos Conceitos de Reflexão, Kant examina o erro produzido pela confusão entre as faculdades do entendimento e da sensibilidade, um erro que leva a tomar os objetos do conhecimento, os fenômenos, por coisas em si e, com isso, conduz as faculdades de conhecimento a transgredir os limites da experiência possível estabelecidos na Estética e na Lógica Transcendental de sua Crítica da Razão Pura. Este trabalho busca mostrar que, além de uma crítica tanto ao empirismo de Locke quanto ao inatismo de Leibniz, a Anfibolia é a seção que Kant dedica a uma avaliação da epistemologia desenvolvida na Crítica em termos de seu caráter e resultados e do confronto com essas duas grandes epistemologias. Mostraremos que, embora acuse tanto Locke quanto Leibniz do erro anfibológico, Kant se concentra na crítica a Leibniz justamente na medida em que essa crítica o aproxima da epistemologia empirista e sua rejeição a toda ontologia do sujeito.
\end{abstract}

Palavras-ChaVe: anfibolia; conceitos da reflexão; metafísica; Kant
ABSTRACT: In the section on the Amphiboly of the Concepts of Reflection, Kant examines the mistake that results from the confusion in the roles of the faculties of understanding and sensibility, a mistake that leads to taking the objects of knowledge, the phenomena, for things in themselves and, thereby, induces the faculties of knowledge to transcend the limits of possible experience established in the Transcendental Aesthetic and Logic of his Critique of Pure Reason. This paper will show that, besides a critique of both Locke's empiricism and Leibniz's innatism, the Amphiboly is the section in which Kant deals with the evaluation of the nature and results of the epistemology he develops in the Critique and in which he confronts it with these two great epistemologies. We will show that, although he attributes to both Locke and Leibniz the amphibological mistake, Kant focuses his criticism on Leibniz insofar as this critique brings him closer to the empiricist epistemology and its rejection of all ontology of the subject.

KEYWORDS: amphiboly; concepts of Reflection; metaphisics; Kant

\section{A Anfibolia e os Limites da ExperiênCia}

$\mathrm{K}$ ant denomina Anfibolia o apêndice que ele acrescenta à parte final da Analítica Transcendental, no qual ele confronta suas teses relativas ao conhecimento dos objetos da experiência diretamente com as teses empiristas de Locke, mas sobretudo, com as de Leibniz. Seguindo seu procedimento habitual de

* * Professora de Filosofia no Departamento de Filosofia e no Programa de Pós-Graduação de Filosofia da Universidade Federal da Paraíba. Doutora em Filosofia pela Universidade de São Paulo-USP.m@iltoklcescato@gmail.com 
recorrer à terminologia e às distinções da lógica formal clássica, ou "lógica geral" para usar a terminologia do próprio Kant, ele toma de empréstimo à lógica o termo que designa a falácia baseada na ambiguidade da estrutura gramatical, que resulta na distorção ou imprecisão da inferência lógica. Na medida em que a lógica transcendental não se restringe às leis formais do pensamento, mas deve levar em conta a referência a priori dessas leis aos objetos, a anfibolia transcendental designa, agora, não o erro resultante da ambiguidade lógica, mas o erro produzido pela confusão do "objeto do entendimento puro com o fenômeno" (A 270/B 326), pela atribuição incorreta de representações dadas às diferentes faculdades de conhecimento, resultando no uso da razão teórica além dos limites da experiência possível.

\section{A Anfibolia e os Limites da ExperiênCia}

Kant denomina Anfibolia o apêndice que ele acrescenta à parte final da Analítica Transcendental, no qual ele confronta suas teses relativas ao conhecimento dos objetos da experiência diretamente com as teses empiristas de Locke, mas sobretudo, com as de Leibniz. Seguindo seu procedimento habitual de recorrer à terminologia e às distinções da lógica formal clássica, ou "lógica geral" para usar a terminologia do próprio Kant, ele toma de empréstimo à lógica o termo que designa a falácia baseada na ambiguidade da estrutura gramatical, que resulta na distorção ou imprecisão da inferência lógica. $\mathrm{Na}$ medida em que a lógica transcendental não se restringe às leis formais do pensamento, mas deve levar em conta a referência a priori dessas leis aos objetos, a anfibolia transcendental designa, agora, não o erro resultante da ambiguidade lógica, mas o erro produzido pela confusão do "objeto do entendimento puro com o fenômeno" (A 270/B 326), pela atribuição incorreta de representações dadas às diferentes faculdades de conhecimento, resultando no uso da razão teórica além dos limites da experiência possível.

Esses limites da experiência possível Kant acredita ter estabelecido nas análises da Estética e da Analítica Transcendental. É dessa Analítica Transcendental que a discussão da Anfibolia Transcendental faz parte como apêndice. A Anfibolia tem então a função de extrair os últimos resultados da elaboração do conceito de experiência possível e da análise dos conceitos e princípios a priori que constituem a forma e a unidade da experiência, em resultado da restrição do conhecimento dos objetos aos limites da experiência possível.

\section{A Anfibolia e os ObJetos em Si}

No último capítulo da Analítica dos Princípios, dedicado à análise da distinção dos objetos em phaenomena e noumena, Kant examinava a ambiguidade que se produz quando o entendimento designa o objeto como fenômeno (A 236-60/B 294-315). Essa designação refere-se ao objeto na medida em que dado numa determinada relação, a relação de afecção na qual ele se torna objeto para o sujeito, na experiência. No entanto, nesse mesmo ato, diz-nos Kant, o entendimento "produz ainda, ao mesmo tempo [...] fora dessa relação, a representação de um objeto em si mesmo e termina por representar a si próprio como capaz de formar conceitos de um tal objeto" (B 306-7). O entendimento vai então em busca de um conhecimento inteligível puro, que seria dado no uso de seus conceitos a priori, as categorias, para conhecer objetos aos quais o entendimento teria acesso por meio apenas de seus conceitos.

Nesse momento, o entendimento ultrapassa todos os limites estabelecidos pela 
Analítica Transcendental quanto à possibilidade da experiência e ao âmbito de aplicação das categorias. Pois o conceito de númeno assim extraído analiticamente tem sentido apenas negativo: ele é o conceito de algo pensado como "objeto de uma intuição não sensível" (B 307) e, como tal, indica uma esfera de objetos que teríam de ser dados a uma forma de intuição que não a nossa, que é sempre sensível e depende, portanto, da faculdade que dá acesso a objetos sensíveis, a sensibilidade. Ele é o conceito problemático de um objeto que pode ser pensado sem contradição, mas cuja realidade objetiva não pode ser estabelecida, já que requer uma forma de intuição a nós inacessível. No entanto, ele pode se conectar a outros conhecimentos e servir para limitar o uso dos conceitos neles envolvidos. É desse modo que o conceito de númeno permite restringir a validade objetiva do conhecimento sensível aos objetos da intuição sensível e excluir do âmbito do conhecimento e da experiência possível o conhecimento das coisas em si mesmas. E Kant é categórico a esse respeito:

[...] em definitivo, não é possível compreender a possibilidade de tais númenos e o que se estende para além da esfera dos fenômenos é (para nós) vazio; quer dizer, temos um entendimento que, problematicamente, se estende para além dos fenômenos, mas não temos nenhuma intuição, nem sequer o conceito de uma intuição possível, por meio da qual nos seriam dados objetos fora do campo da sensibilidade de modo que, assim, o entendimento poderia ser usado assertoricamente para além da sensibilidade (B 310, A 255).

Por isso Kant caracteriza o númeno como "mero conceito limite" (A 255/B 311). Ele é o conceito que se conecta à sensibilidade para restringir o conhecimento humano aos limites do conhecimento sensível, sem no entanto povoar um domínio além desses limites com um mundo de objetos em si.

A anfibolia é a retomada desse diagnóstico da ambiguidade no uso dos conceitos puros que Kant detecta provir da confusão nas distinções: sensibilidade e entendimento, fenômeno e coisa em si. A reflexão transcendental é o procedimento que permite determinar a fonte do conhecimento à qual devem ser atribuídos cada um desses conceitos e, com isso, torna possível evitar o erro anfibológico, pois ela estabelece os limites do uso deles, ao atribuir ao conceito de númeno a mera função negativa de restringir esse uso ao âmbito da experiência possível. Foi por não fazer a correta distinção sensibilidade-entendimento que Leibniz terminou por cair na anfibolia e confundir o âmbito de aplicação desses conceitos, dando uso positivo a um conceito de função meramente negativa.

As análises da Anfibolia constituem um complemento a esse diagnóstico, examinando como Locke e Leibniz terminaram por introduzir a anfibolia em suas análises do conhecimento, por não distinguir nitidamente entre sensibilidade e entendimento. Com isso, eles privilegiaram exclusivamente uma dessas duas faculdades e igoraram que, somente em conexão, essas duas fontes de conhecimento podem produzir conhecimento objetivo (A 271/B 327). Assim, em resultado da anfibolia, as análises de Locke ignoraram a contribuição do entendimento e fizeram dele uma faculdade responsável meramente pela ordenação das representações fornecidas pela sensibilidade, fazendo de todo conhecimento um conhecimento empírico, ou de “conceitos abstraídos da reflexão" (A 271/B 327). Leibniz, por seu lado, concluíu que o entendimento poderia conhecer as coisas em si apenas pelo uso do entendimento, sem necessidade da mediação da sensibilidade fornecendo as representações dos objetos, e com isso construíu seu "sistema intelectual do mundo" (A 270/B 326), conhecido pelo entendimento unicamente.

Embora atribua tanto a Locke quanto a Leibniz o erro anfibológico, Kant 
menciona Locke uma única vez, na Nota à Anfibolia dos Conceitos de Reflexão, dirigindo o peso de suas análises à anfibolia produzida por Leibniz. São quatro os títulos nos quais Kant examina as teses leibnizianas resultantes da anfibolia.

1. A distinção identidade e diversidade na tese da identidade dos indiscerníveis. O princípio dos indiscerníveis é sem dúvida um princípio válido para coisas em si, na medida em que elas devem ser objetos para o mero pensamento, mas não para os objetos dados no espaço e no tempo. De acordo com Kant, Leibniz aplica esse princípio aos fenômenos porque, não distinguindo adequadamente entre sensibilidade e entendimento, ele termina por tomar os fenômenos por coisas em si, ou objetos inteligíveis do entendimento puro.

2. O contraste entre concordância e oposição na distinção entre oposição real e oposição lógica. Se o objeto é representado apenas no pensamento (realitas noumenon) então não pode haver oposição real, mas apenas lógica, e o resultado é o nada absoluto ou "nihil privativum irrepresentabile", como exprime o princípio de contradição". Exemplo dessa forma de oposição está na ideia de um corpo pensado como, ao mesmo tempo, em movimento e em repouso. Assim, quando Leibniz afirma que as realidades nunca se opõem essa é uma proposição verdadeira apenas com relação aos conceitos e a oposição é meramente lógica. Mas os objetos enquanto fenômenos (realitas phaenomenon) podem sem dúvida entrar em oposição real e anular um o efeito do outro, como por exemplo duas forças motoras que, atuando sobre uma reta, podem puxar ou impelir um ponto na direção oposta; ou o prazer como compensação da dor (A 265/B 321: exemplos fornecidos pelo próprio Kant).

3. A distinção externo e interno no conceito de mônada. Como objeto do entendimento puro, toda substância deve ter determinações internas e forças que pertencem a sua realidade interna. Mas quais seriam os "acidentes internos que meus sentidos internos oferecem a não ser o que é ele próprio um pensamento ou algo análogo ele"? (A 265-66/B 321-22). No entanto, como representou as substâncias como númenos, com isso suprimindo delas tudo que significa uma relação ou composição, Leibniz as transformou em sujeitos simples dotados da capacidade de representação, isto é, mônadas (A 282-86/B 338-42). Na medida em que os únicos objetos dados a nossa sensibilidade são fenômenos, eles não são constituídos por forças internas, mas apenas por forças relacionais. Portanto esse sujeito dado ao sentido interno não pode ser caracterizado como a mônada leibniziana: ele é fenômeno, tanto quanto o pedaço de cera que Descartes analisa em suas Meditações.

4. A distinção forma e matéria na determinação dos conceitos de espaço e tempo. $\mathrm{Na}$ medida em que no conceito puro do entendimento a matéria (as características essenciais do conceito) precede a forma (o modo como as características são conectadas numa unidade), Leibniz atribuíu às coisas (= mônadas) uma capacidade interna de representação, para então fundar a relação externa e a comunidade de seus estados representativos. Disso ele derivou os conceitos de espaço e de tempo: o espaço como a relação entre as substâncias e o tempo como a conexão das determinações das substâncias como fundamento (Grund) e consequências (Folgen). Isso seria verdadeiro, observa Kant, se o entendimento se referisse diretamente aos objetos, sem mediação, e se o espaço e o tempo fossem determinações das coisas em si. Mas, na medida em que os objetos são dados como intuições sensíveis e, dessa forma, como fenômenos, a forma (subjetiva da sensibilidade) deve preceder toda matéria (as sensações), de modo que são o espaço e o tempo que precedem os os fenômenos e os dados da experiência e tornam possíveis esses fenômenos (A 267/B 323). Assim, contra a tese de que espaço e tempo são extraídos das relações entre as substâncias, espaço e tempo devem ser considerados formas da intuição que são pressupostas em toda representação de objetos, 
na medida em que elas são a condição da representação deles como objetos dados na experiência. Anteriores portanto aos objetos, e não extraídas deles, como pretendia Leibniz.

\section{O Ponto de Vista Epistemológico da Anfibolia}

Sobre essas teses leibnizianas, Kant observa que elas seriam verdadeiras se os objetos fossem coisas em si e objetos do entendimento puro. Na medida em que, no entanto, os objetos do conhecimento humano são determinados no espaço e no tempo e, assim, dados como fenômenos à sensibilidade, eles não podem ser representados como objetos do entendimento puro, isto é como mônadas. Evidentemente essas conclusões se apóiam, de um lado, na distinção kantiana entre sensibilidade e entendimento, e de outro, na tese a ela correlacionada, distinguindo fenômeno de coisa em si e dependem, portanto, das demonstrações da Estética Transcendental e da derivação nela estabelececida da tese da idealidade transcendental do espaço e do tempo.

Ao caracterizar os objetos do conhecimento humano como objetos dados à sensibilidade sob as formas subjetivas e a priori do espaço e do tempo, Kant pode excluir as coisas em si da esfera dos objetos do conhecimento. A crítica kantiana a Leibniz se baseia nessas distinções. Por ter entendido que os objetos reais eram a mônadas, diz-nos Kant, Leibniz atribuíu a elas capacidades representacionais e as caracterizou como substâncias pensantes. Mas as análises da Crítica da Razão Pura evidenciam que tal caracterização do sujeito está fora dos limites do conhecimento do objetos, já que não é possível ao sujeito humano representar e conhecer os objetos fora das condições formais da sensibilidade, que são o espaço e o tempo. Se há um conhecimento desse sujeito, esse conhecimento deve ser o conhecimento de um objeto como fenômeno, dado à experiência no sentido interno (sob a forma a priori do tempo), tanto quanto qualquer objeto dado como exterior à mente no sentido externo (sob a forma a priori do espaço). Tal conhecimento não faria parte da filosofia, mas constituiria uma disciplina à parte, talvez uma psicologia empírica, aventa ele mais de uma vez no capítulo dos Paralogismos, na Dialética Transcendental da Razão Pura. Em consequência, a divergência de Kant com relação a Leibniz se concentra em torno do estatuto representacional dos objetos no espaço e no tempo ou como mônadas e na substancialidade do sujeito pensante.

Em seu Kant and the Capacity to Judge ${ }^{2}$, Béatrice Longuenesse examina as teses da Anfibolia, com o objetivo de investigar como as operações de reflexão permitem a Kant explicar a passagem da síntese prediscursiva, na qual os dados sensíveis são determinados como objetos da percepção, para a produção dos conceitos que serão ligados em proposições ou juízos e sem os quais não seria possível o conhecimento discursivo dos objetos dados na experiência. Essa é uma abordagem fundamental, já que sem esses conceitos e proposições não seria possível formular discursivamente o conhecimento dos objetos dados na experiência.

Nossas análises aqui têm, ao contrário, um alcance mais modesto. Queremos chamar a atenção para o modo como o exame de Kant dos conceitos de reflexão permite a ele distinguir sua análise do conhecimento dos objetos com relação à análise de Leibniz, em virtude da qual os argumentos finais da Analítica Transcendental são caracterizados como "reflexão transcendental" (A 261/B 317). As análises da Anfibolia constituem o momento que Kant reserva para o confronto de sua epistemologia com a de Leibniz (embora também com a de Locke). O objetivo é esclarecer pontos específicos de sua epistemologia e estabelecer as principais divergências com relação a 
esses dois adversários - e evidentemente, sobretudo, Leibniz.

É verdade que Kant e Leibniz permanecem muito próximos quando enfatizam a dependência do conhecimento dos objetos com relação a um sujeito que ordena esse conhecimento por meio de um conjunto de capacidades representacionais que fazem do conhecimento, irredutivelmente, o conhecimento de um mundo de objetos - para um sujeito. Mas enquanto Leibniz substancializa esse sujeito em vista de atribuir a ele capacidades inatas e, com isso, garantir a validade e necessidade das representações responsáveis pela objetividade do conhecimento, Kant restringe sua epistemologia à análise das capacidades cognitivas e de suas representações e se recusa a fundar a necessidade e objetividade dessas representações numa ontologia do sujeito. A análise epistemológica deve se restringir então ao explicitar das diferentes funções que esse sujeito deve utilizar ao ligar suas representações no conhecimento dos objetos. Uma exigência que seu outro adversário, Locke, formulava como o exame das "capacidades da mente" que deve esclarecer as diferentes "operações da mente" envolvidas no conhecimento empírico dos objetos e que, também Locke, atribuía a uma capacidade, ou operação da mente, denominada reflexão ${ }^{3}$.

\section{KANT E A EPISTEMOLOGIA EMPIRISTA}

Não vamos aqui nos deter no exame da concepção de Locke de reflexão e do uso que ele faz dela em sua teoria do sujeito e da mente. Queremos apenas destacar a proximidade do projeto kantiano de crítica da razão com a epistemologia empirista inaugurada por Locke. Sem dúvida, há um abismo entre a concepção de reflexão de Kant e a de Locke. Para começar, o que faz da epistemologia de Locke, tanto quanto a de Leibniz, objeto da crítica de Kant na Anfibolia: não distinguir adequadamente entre sensibilidade e entendimento e, em consequência, atribuir à sensibilidade e à experiência o que somente pode ser do âmbito do entendimento. Mas a proximidade no uso da terminologia permite perceber que é justamente o ponto que ele critica em Leibniz que o aproxima dos empiristas: a recusa em sustentar a análise do conhecimento numa ontologia da substância e a decisão deliberada de restringir a epistemologia à investigação das operações da mente responsáveis pelo conhecimento dos objetos. Não apenas Locke mas também Hume ${ }^{4}$ vão analisar o sujeito do conhecimento e seu objeto como constituindo complexos empíricos, não substanciais, que são designados por um "eu" uno e idêntico apenas na medida em que as representações desse sujeito devem referidas a um "eu” que pensa essas representações.

Assim, ao analisar as operações da mente que produzem a ideia complexa de substância em geral, Locke mostra que essa ideia é formada pela observação na experiência da conjunção constante entre certas ideias. A mente então presume que essas ideias em conjução constante estão conectadas como pertencendo "a uma coisa" (Ensaio II, Cap. XXII, § 1) e atribui-lhes um mesmo nome. Pelo uso de um mesmo nome para designar conjuntos de ideias em conjunção constante, a mente se refere a elas como "unidas em um sujeito" e é, com isso, induzida a "inadvertidamente [...] falar e considerar" (idem) esse complexo de ideias como a ideia simples de algo presente a sua percepção. Isso porque, não tendo como explicar como essas ideias podem subsistir por si sós, a mente é levada a supor um substrato no qual elas subsistem e do qual elas dependem e termina por designar essa ideia assim construída pelo nome de substância. Essa ideia assim formada, no entanto, não se refere a nenhum objeto de nossa percepção ou experiência, mas apenas à unidade desses complexos de ideias em conjunção constante. É a essa unidade que damos o nome de "substância". Mas, diz-nos 
Locke, essa ideia constitui apenas uma "ideia obscura" da qual temos necessidade em vista de explicar e ordenar nossas representações. Assim ele observa:

Apenas é preciso observar que nossas idéias complexas das substâncias, além de todas as idéias simples que as constituem, sempre são acompanhadas da ideia confusa de algo ao qual elas pertencem e no qual elas subsistem: e, dessa forma, quando falamos de algum tipo de substância, estamos dizendo que é uma coisa dotada de tais ou tais qualidades; da mesma forma que um corpo é uma coisa que é extensa, dotada de uma forma espacial e capaz de movimento; espírito, uma coisa capaz de pensar; da mesma forma, dizemos que a dureza, o ser quebradiça e a capacidade de atrair o ferro são qualidades que se encontram na magnetita. Esses e outros modos de falar sugerem que estamos fazendo a suposição de que a substância é sempre algo além da extensão, da forma espacial, da solidez, do movimento, do pensamento ou outras idéias observáveis, embora não saibamos o que ela é (Locke, Ensaio, II, cap. XXIII, § 3, itálicos nossos).

Locke analisa então o conceito de eu substancial da tradição inatista como uma instância particular da ideia assim formada de substância em geral. Mas em vez de complexos de ideias de objetos exteriores à mente, o complexo de ideias que vai constituir esse eu substancial é dado pela atividade da mente de reflexão sobre suas próprias operações. Ao observar, pela reflexão sobre as operações da mente de pensar, raciocinar, imaginar e assim por diante, e concluir que essas operações não subsistem por si sós, nem pertencem ou são produzidas pelo corpo, nós as atribuímos a uma substância que as produziria e na qual elas subsistiriam e a denominamos espírito. Mas essas análises deixam evidente que essa ideia de substância é produzida pelas operações da mente que, apoiada na ideia de "algo no qual essas diversas qualidades sensíveis que afetam nossos sentidos subsistem" (Locke, Ensaio, II, § 5), termina por "supor uma substância na qual o pensamento, o conhecimento, a dúvida e a capacidade de movimento etc. subsistem" (idem). Mas essa ideia é um produto da mente, em vista de preencher uma lacuna nos dados perceptivos que ela obtém quando observa suas próprias operações e não nos fornece qualquer ideia clara de uma substância pensante à qual teríamos acesso pela reflexão sobre a atividade da mente quando pensa.

É nesse ponto que as análises de Kant se alinham com o empirismo de Locke e colocam em destaque o desacordo com Leibniz e a tradição inatista: apoiar a análise do conhecimento no conceito de um eu substancial e na análise de suas ideias inatas é recorrer a um conceito obscuro para o qual não é possível estabelecer a legitimidade. As análises da Anfibolia constituem o momento da Crítica em que essa divergência vem para o primeiro plano. Mas elas também permitem perceber que, ao criticar Locke em paralelo com Leibniz na Anfibolia, Kant mostra ter levado a sério não apenas as análises de Hume - que o "despertou do sono dogmático" - mas sobretudo as do próprio Locke.

\section{REFERÊNCIAS}

KANT. Kritik der reinen Vernunft, Hamburgo, Felix Meiner, 1998. Philosophiches Bibliothek, vol. 505.

LEIBNIZ, G. W. Nouveaux Essais sur l'entendement humain. Wikisource, URL: https://fr.wikisource.org/wiki/Nouveaux_Essais_sur_1\%E2\%80\%99entendement_humain, consultado em, 04.06.2018, $15 \mathrm{~h} 37$.

LOCKE, J. An Essay Concerning Human Understanding. Adelaide E-Books, IRL: https://ebooks.adelaide.edu.au/l/locke/john/181u/contents.html, consultado em, 04.06.2018, $15 \mathrm{~h} 41$. 


\section{Referência secundária:}

BROOK, Andrew. "Kant's Attack on Leibniz's and Locke's Amphibolies". In: Palmquist, Stephen (org). Cultivating Personhood, Berlin, de Guyter, 2010, pp. 140-154.

LONGUENESSE, Béatrice. Kant and the Capacity to Judge: Sensibility and Discursivity in the Transcendental Analytic of the Critique of Pure Reason. Trad. do frances: Charles T. Wolfe. Princeton, Princeton Uni. Press, 1998.

McROBERT, Jennifer e Brook, Andrew. "Kant's Attack on the Amphiboly of the Concepts of Reflection". In: The Paideia Project. Twentieth World Congress of Philosophy, in Boston, Massachusetts from August 10-15, 1998. URL: http://www.bu.edu/wcp/Papers/TKno/TKnoBroo.htm, consultado em: 04.06.2018, 15h11.

NUNZIANTE, Antonio-Maria e Vanzo, Alberto. "Representing Subjects, Mind-dependent Objects. Kant, Leibniz, and the Amphiboly". In: British Journal for the History of Philosophy, 17, 2009, pp. 133-151. Também disponível online, na URL: http://www.tandfonline.com/doi/abs/10.1080/09608780802548390?scroll=top\&needAcce ss=true\&journalCode=rbjh20, consultado em, 04.06.2018, $15 \mathrm{~h} 19$.

PEREBOOM, Derk. "Kant's Amphiboly”. In: Archiv für Geschichte der Philosophie 73, 1991, pp. 50-70. Disponível online, na URL: https://www.deepdyve.com/lp/de-gruyter/kant-samphiboly-q2cdr8r2VK, consultado em, 04.06.2018, $15 \mathrm{~h} 23$.

\section{NoTAS}

1 KANT, I. "Ensaio para Introduzir a Noção de Grandezas Negativas em Filosofia" (1763). Tradução de Vinícius de Figueiredo e Jair Barboza. In: Kant, I. Escritos Precríticos. São Paulo, Editora da UNESP, 2005, p. 51-99.

2 LONGUENESSE, Béatrice. Kant and the Capacity to Judge: Sensibility and Discursivity in the Transcendental Analytic of the Critique of Pure Reason. Trad. do frances: Charles T. Wolfe. Princeton, Princeton Uni. Press, 1998.

3 LOCKE, J. Essay concerning Human Understanding (1689), Adelaide, AU, The University of AdelaideLibrary,eBooks@Adelaide,2015,URL:

https://ebooks.adelaide.edu.au/1/locke/john/181u/index.html.

4 Por exemplo, toda a discussão sobre o conceito de identidade pessoal na seção VI do Livro I, do Tratado do Entendimento Humano. 